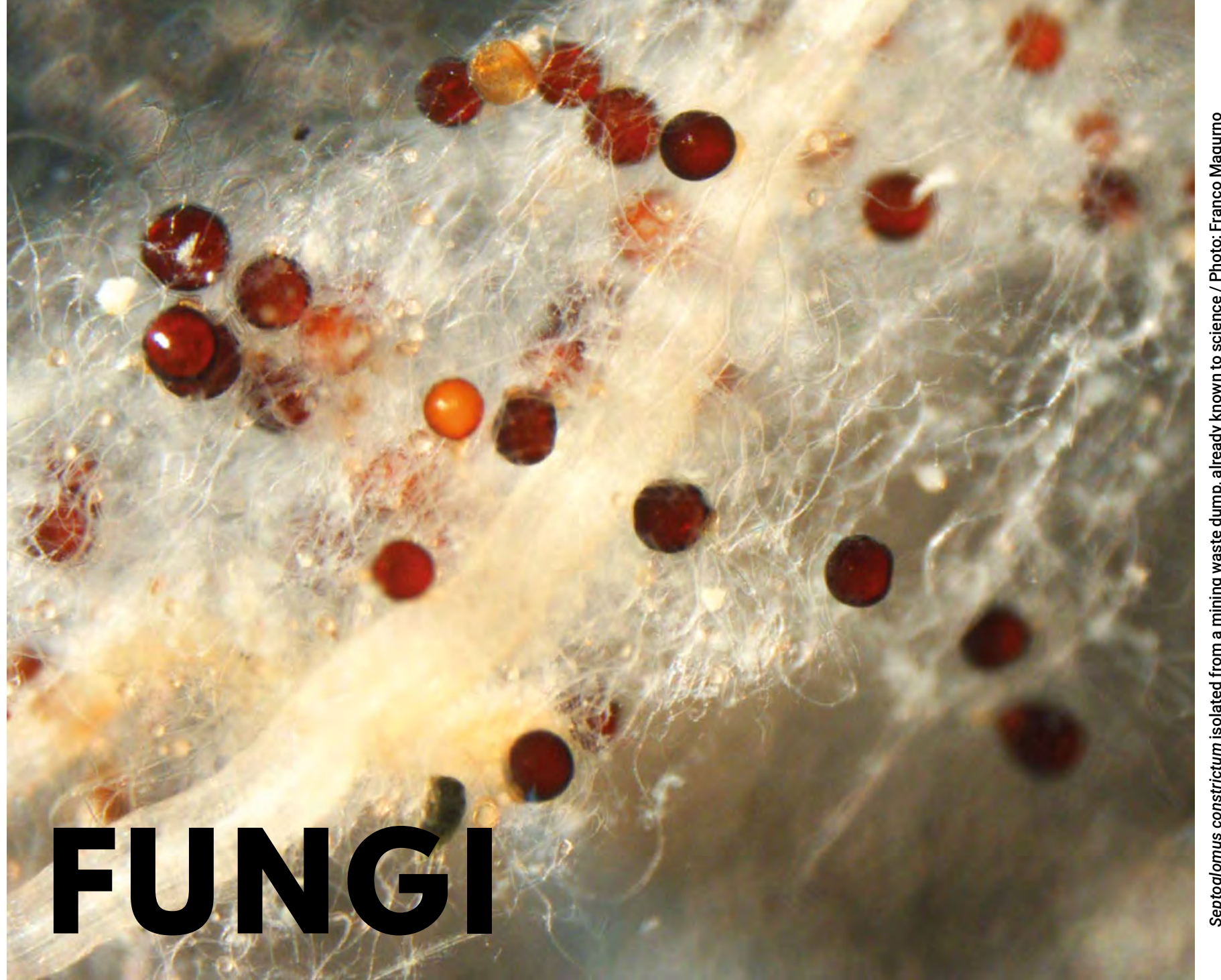

\title{
in the Revitalization of Post-industrial Areas
}

text: Maria Sztuka

Climate change has become a fact, and people all over the globe can feel the effects of this process. Longterm droughts are particularly dangerous, since they not only negatively affect the development of plants, but also cause many diseases that are dangerous for them. The intensive use of fertilizers and pesticides or land reclamation, measures intended to support agricultural production, have proven to be extremely harmful to the soil. Moreover, in many places they have led to its degradation. A large part of the world is struggling with a lack of proper hydration, and the process of desertification is beginning to threaten all continents. The research results of interdisciplinary scientific teams who focus on countering the devastation of nature and restoring vital biodiversity are not only carefully followed, but also applied immediately if possible. 
Due to the specific way natural deposits are exploited in Silesia, this region is a very promising research field. Mine waste dumps (tips) have become laboratories for scientists specializing in urban vegetation, post-industrial areas, plant physiology, and soil microbiology, including research on mycorrhiza. These remnants of mining attracted scientists' attention, since they make it possible to look for changes in plant cover under the influence of anthropopressure as well as for hint on supporting the process of revitalization of post-industrial areas.

The dumps will not disappear by themselves. Without human intervention, they are bound to become a huge threat to surface and deep water as well as to atmospheric air, and therefore these sites have a decisive impact on climate change and the quality of life on Earth. For many years, scientists from the Institute of Biology, Biotechnology and Environmental Protection of the Faculty of Life Sciences of the University of Silesia have been conducting research aimed at developing the most effective methods of reclamation and management of mine waste dumps. A research team led by Assoc. Prof. Gabriela Woźniak from the University of Silesia completed the implementation of a long-term research project (System of supporting revitalization of post-mining waste dumps with the use of geoinformatic tools). The specialists from various disciplines focused on the recognition of spontaneously occurring biological processes in the dumps, which allowed to identify the ways to strengthen and accelerate them.

The samples taken from the waste dumps contain an abundance of research material, and since plants living on these post-mining sites face similar problems as plants living in desert areas, they have to struggle for survival under the stress of water, micronutrients, and nutrient deficiencies. Therefore, the research results (concerning e.g. relations between plants, their abundance, diversity, biomass, and substrate) can be applied to equally difficult terrains on different continents.

Among other results, the research has enabled scientists to point out the special role of fungi in the revitalization process. This was the task of microbiologist Dr. Franco Magurno, whose research interests focus on mycorrhiza, the symbiosis between roots of vascular plants and some fungi. After isolating them from the dumps, the microbiologist will verify if they could be used in other areas.

The scientist focused particularly on arbuscular mycorrhiza, where the fungal hyphae penetrate the plant root cells. A characteristic element in this type of mycorrhiza is arbuscules produced as lateral branches of fungal hyphae inside plant cells. They have a tree-like shape and are tightly surrounded by a plant cell membrane, a circumstance that significantly increases the surface area constituting the zone in which partners exchange substances. According to several studies, arbuscular mycorrhiza is the most primordial type of mycorrhizal symbiosis occurring between fungi and plants. Moreover, this phenomenon is probably the reason why plants came out on land.

"Without these fungi, plants would not have been able to colonize easily the land. It turns out that a large part of the plant genome is genes responsible for the synthesis of proteins involved in the sym- biosis. From the point of view of plants, mycorrhiza is very important, since this process helps them survive in difficult conditions, such as drought or lack of micronutrients," the microbiologist explains. One of the most important features of arbuscular fungi is the possibility to prevent infection by pathogenic fungi, since they are able to defend plants against many dangerous diseases.

It is worth noting that Rhizoglomus silesianum was added to the atlas of arbuscular fungi. Dr. Franco Magurno and Dr. Monika Malicka isolated this species from materials obtained at the Makoszowy mine waste dump, in an environment with high salinity and small amount of water, i.e. under conditions that prevail under the stress of drought. Hopefully Rhizoglomus silesianum will be useful for the production of inocula to replace synthetic fertilizers and pesticides. This feature makes it highly desirable for agriculture.

\section{- Dr. Franco Magurno Institute of Biology, Biotechnology and Environmental Protection Faculty of Natural Sciences University of Silesia franco.magurno@us.edu.pl}

\section{Rhizoglomus silesianum / Photo: Franco Magurno}

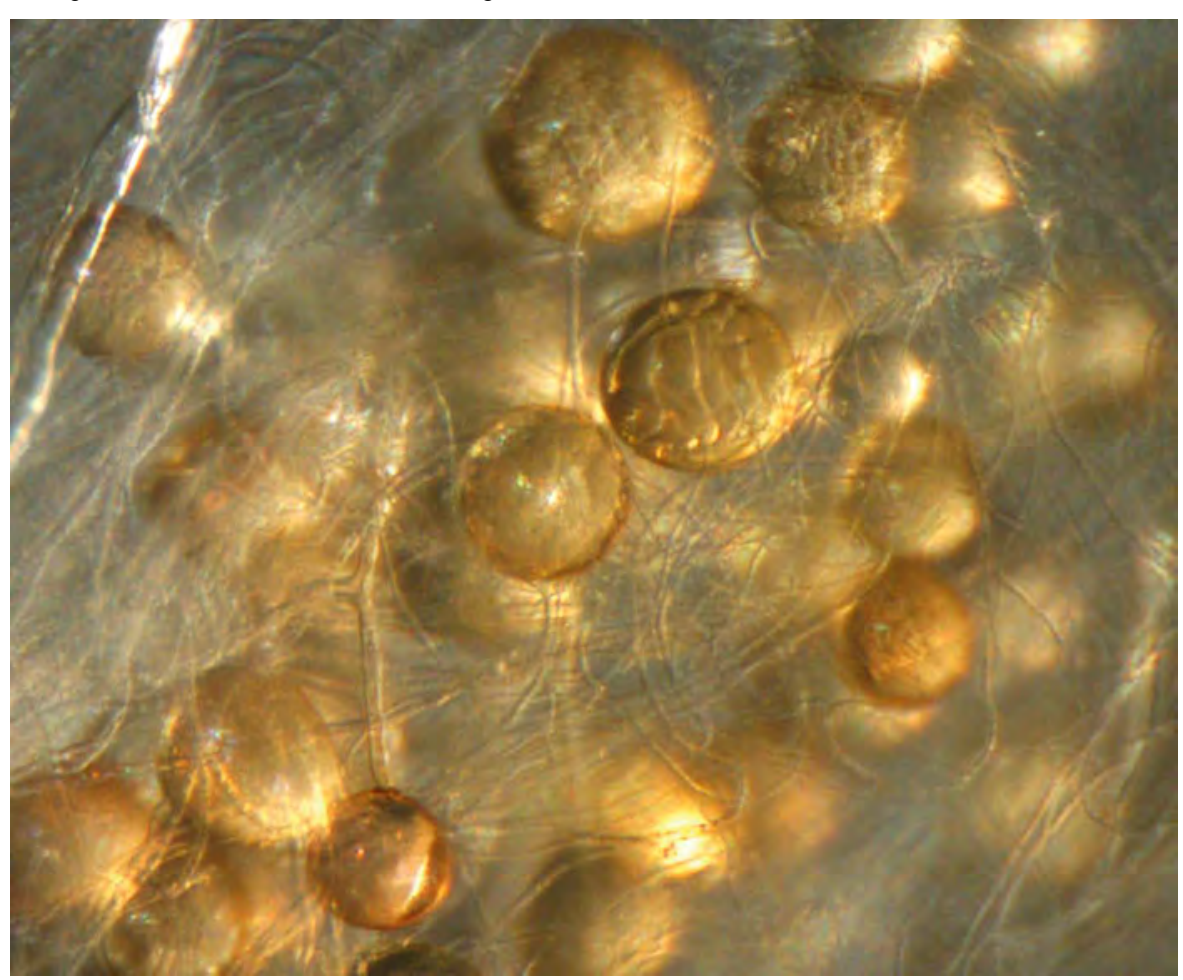

